\title{
Chronic idiopathic bronchiolitis of infancy
}

\author{
J Hull, C W Chow, C F Robertson
}

\begin{abstract}
The clinical and morphological features are presented of eight infants who developed a chronic respiratory illness in the first year of life characterised by tachypnoea and inspiratory crackles on auscultation. The median age at the onset of symptoms was 1 month (range 1 day to 7 months). Five of the infants required supplemental oxygen. Chest radiographs showed only non-specific perihilar alveolar shadowing and generalised hyperinflation. Investigations into the cause of the illness in these infants, including studies for infection, cardiac disease, and gastrooesophageal reflux, were negative, and an open lung biopsy sample was subsequently taken from each infant. Histological examination showed mild lymphocytic bronchiolar infiltration only in six of the eight infants. The other two biopsy samples were normal. Seven of the infants were given a trial of steroids by mouth (mean duration of treatment four months) without any apparent benefit. These infants have now been followed up for a median duration of 21 months (range 1-9 years). All have shown continuous improvement, with either the end of oxygen treatment (three patients) or the use of low flow oxygen only at night (two patients). All have normal development and all but one have normal growth. Chest examination has become normal in four subjects. In the remainder the inspiratory crackles have persisted, although they have decreased markedly in all patients. It is proposed that these infants have a previously unreported respiratory entity and that the clinical and lung biopsy sample findings reported here predict a favourable medium term prognosis. (Arch Dis Child 1997;77:512-515)
\end{abstract}

Royal Children's Hospital, Melbourne, Australia: Department of Thoracic Medicine J Hull

C F Robertson

Department of Pathology

C W Chow

Correspondence to: Dr Jeremy Hull, Department of Paediatrics, Level 4 , John Radcliffe Hospital, Headington, Oxford OX3 9DU.

The development of chronic respiratory disease in a previously well infant is unusual in the first year of life. There are several possible causes, including bronchiolitis obliterans after a severe viral infection, fibrosing alveolitis and other forms of pulmonary interstitial fibrosis, primary ciliary dyskinesia, and aspiration lung disease. Pulmonary vascular disease, associated with congenital heart defects, can also present as respiratory distress. All of these diseases present characteristic features when a lung biopsy sample is taken, or have definable ciliary abnormalities.
We report here the cases of eight infants who presented to the Royal Children's Hospital, Melbourne over an eight year period with chronic respiratory symptoms (at least four weeks in duration) similar to those found in the above mentioned diseases, but in whom no clear aetiology could be established. Lung biopsy samples showed a mild lymphocytic bronchiolitis only. The disease in these infants has subsequently followed a relatively benign course. The purpose of this report is to suggest that this illness may represent a hitherto unrecognised entity and that although no aetiology has been established, the presence of these findings in lung biopsy samples indicates a relatively good prognosis in this group of infants.

\section{Methods}

The children in this study were identified by a retrospective review of infants referred to the department of thoracic medicine at the Royal Children's Hospital, Melbourne over the period 1988 to 1995 for investigation of tachypnoea of greater than two weeks' duration, and who had inspiratory crackles on examination or a requirement for supplemental oxygen for longer than one week. Infants are included in this report if a lung biopsy sample was taken as part of their assessment and if, after investigations were complete, no obvious cause for their lung disease was found.

\section{Results}

CLINICAL PRESENTATION

Eight infants were identified. Seven were born at term and the eighth was born at 35 weeks' gestation. This infant (patient 2) required oxygen for the first 24 hours of life, but had no further respiratory problems until the age of 4 months. All the infants had tachypnoea when first seen. Seven of the eight infants had inspiratory crackles on auscultation. Two had wheezing. Five were below the 10th centile for weight. Five required supplemental oxygen to maintain their oxygen saturation above $92 \%$ in room air. Table 1 gives the details of each infant at presentation.

\section{INVESTIGATIONS}

Table 2 summarises the investigations carried out on these infants. Investigations were initially directed at attempting to identify the presence of infection. Repeated nasopharyngeal aspirates for respiratory viral (respiratory syncytial virus; parainfluenzae 1,2 , and 3 ; influenzae A and B; adenovirus, plus cytomegalovirus) immunofluorescence and culture were negative on all occasions in five infants. In patients 2 and 7 the nasopharyngeal aspirate 
Table 1 Summary of the clinical features

\begin{tabular}{|c|c|c|c|c|}
\hline $\begin{array}{l}\text { Patient No } \\
\text { (sex) }\end{array}$ & $\begin{array}{l}\text { Age at onset } \\
\text { (months) }\end{array}$ & Symptoms and signs & Associated disorders & $\begin{array}{l}\text { Age at lung } \\
\text { biopsy } \\
\text { (months) }\end{array}$ \\
\hline $1(\mathrm{~F})$ & 2 & $\begin{array}{l}\text { Poor feeding and tachypnoea; at } 3 \text { months rib retraction, inspiratory } \\
\text { crackles, and cyanosis }\end{array}$ & None & 3 \\
\hline $2(\mathrm{M})$ & Birth & $\begin{array}{l}\text { Tachypnoea; at } 3 \text { months poor weight gain, rib retraction, inspiratory } \\
\text { crackles, and cyanosis }\end{array}$ & $\begin{array}{l}35 \text { weeks' gestation; birth weight } \\
1690 \text { g, required oxygen for } \\
24 \text { hours only }(\max 28 \%)\end{array}$ & 5 \\
\hline $3(\mathrm{~F})$ & Birth & Tachypnoea; at 5 months rib retration and inspiratory crackles & None & 13 \\
\hline $4(\mathrm{~F})$ & Birth & $\begin{array}{l}\text { Poor feeding, poor weight gain, and tachypnoea; at } 4 \text { months rib retraction, } \\
\text { inspiratory crackles, and cyanosis }\end{array}$ & None & 4 \\
\hline $5(\mathrm{M})$ & 2 & $\begin{array}{l}\text { Poor weight gain and tachypnoea; at } 14 \text { months rib retraction, inspiratory } \\
\text { crackles, and cyanosis }\end{array}$ & None & 17 \\
\hline $6(\mathrm{~F})$ & 4 & Poor weight gain, tachypnoea, and inspiratory crackles & None & 10 \\
\hline $7(\mathrm{M})$ & 7 & Tachypnoea, rib retraction, generalised wheeze, and cyanosis & $\begin{array}{l}\text { Congenital pelviureteric junction } \\
\text { obstruction, left pyeloplasty age } \\
2 \text { months }\end{array}$ & 8 \\
\hline $8(\mathrm{M})$ & Birth & $\begin{array}{l}\text { Tachypnoea, rib retraction, generalised wheeze, and cyanosis; at } 3 \text { months } \\
\text { inspiratory crackles }\end{array}$ & None & 3 \\
\hline
\end{tabular}

viral studies identified respiratory syncytial virus on one occasion only; other nasopharyngeal aspirates both before and after the positive results were negative, and it seems unlikely that respiratory syncytial virus was responsible for the chronic illness, although it certainly could have contributed to any deterioration. Similarly, patient 4 grew parainfluenza type 2 on the first nasopharyngeal aspirate taken at the age of 3 months; a subsequent nasopharyngeal aspirate was negative and a third grew parainfluenza type 3. All three nasopharyngeal aspirates were taken on the same admission, during which this infant also underwent bronchoalveolar lavage and a lung biopsy sample was taken, both of which did not grow bacterial or viral pathogens.

The bronchoalveolar lavage fluid from patient 1 grew Moraxella catarrhalis and a scanty growth of this organism was also identified from the lung biopsy sample. This infant was treated with an intravenous course of antibiotics to which the moraxella was sensitive, without any clinical benefit. Bronchoalveolar lavage fluid from patient 6 grew both Streptococcus pneumoniae and rhinovirus. Lung tissue taken under the same general anaesthetic was sterile and it seems likely that the organisms detected in the bronchoalveolar lavage fluid were upper airway contaminants. Serum samples were taken from each infant to identify cytomegalovirus, Epstein-Barr virus, Chlamydia trachomatis, and Mycoplasma pneumoniae. None of the tests was positive. These results and those from the culture of nasopharyngeal aspirates, bronchoalveolar lavage fluid, and lung biopsy tissue make it unlikely that persistent infection was the cause of the long term respiratory symptoms in these infants.

All infants except patient 8 were born after the development of a screening programme for cystic fibrosis in newborn infants in Victoria, and all seven infants had low (negative) immune reactive trypsin levels in the heelprick blood test. Patients 5, 6, and 8 underwent sweat tests, all of which were normal.

Clinical examination of the cardiovascular system was normal in all eight infants. Seven of eight infants also had a normal echocardiogram. Five of the eight infants underwent at least one investigation to identify gastrooesophageal reflux. Patient 1 had mild reflux

Table 2 Summary of investigations

\begin{tabular}{|c|c|c|c|c|c|c|c|c|}
\hline \multirow[b]{2}{*}{ Investigations } & \multicolumn{8}{|l|}{ Patient No } \\
\hline & 1 & 2 & 3 & 4 & 5 & 6 & 7 & 8 \\
\hline $\begin{array}{l}\text { NPA-viral immunofluorescence } \\
\text { and culture }\end{array}$ & Neg $(\times 2)$ & $\begin{array}{c}2 \text { neg, } 1 \\
\text { RSV }\end{array}$ & Neg & $\begin{array}{l}\text { Para } 2 . \mathrm{Neg}, \\
\text { para } 3\end{array}$ & Neg & Neg & $\begin{array}{l}2 \mathrm{Neg}, 1 \\
\mathrm{RSV}\end{array}$ & Neg \\
\hline $\begin{array}{l}\text { Lung biopsy culture (including } \\
\text { virus and mycobacteria) }\end{array}$ & Scanty $M$ catarrhalis & NG & NG & NG & NG & NG & NG & NG \\
\hline $\begin{array}{l}\text { IgG and IgM for cytomegalovirus, } \\
\text { Epstein-Barr virus, chlamydia, } \\
\text { mycoplasma }\end{array}$ & Neg & Neg & Neg & Neg & Neg & Neg & Neg & $\mathrm{Neg}$ \\
\hline HIV test & ND & $\mathrm{Neg}$ & ND & ND & ND & $\begin{array}{l}\text { Neg } \\
\text { S pneumoniae }+\end{array}$ & $\mathrm{ND}$ & $\mathrm{ND}$ \\
\hline Bronchoalveolar lavage & $M$ catarrhalis++ & NG & NG & NG & ND & rhinovirus & ND & ND \\
\hline Immunoglobulins & NL & NL & ND & NL & NL & NL & ND & NL \\
\hline Screening IRT & NL & NL & NL & NL & NL & NL & NL & ND \\
\hline Sweat test & ND & ND & ND & ND & NL & NL & ND & NL \\
\hline Echocardiography & NL & $\mathrm{NL}$ & $\mathrm{ND}$ & NL & $\begin{array}{l}\text { NL } \\
\text { Mild }\end{array}$ & $\mathrm{NL}$ & NL & NL \\
\hline Barium swallow & Mild reflux & NL & ND & ND & $\begin{array}{l}\text { reflux } \\
17 \%\end{array}$ & NL & $\mathrm{ND}$ & NL \\
\hline pH study & ND & ND & ND & ND & reflux & NL & ND & NL \\
\hline Isotope milk scan & ND & ND & ND & ND & $\begin{array}{l}\text { NL } \\
\text { Mild }\end{array}$ & NL & ND & NL \\
\hline Gastroscopy and biopsy & ND & ND & ND & ND & gastritis & NL & ND & ND \\
\hline$\alpha_{1}$-Antitrypsin & ND & NL & ND & ND & $\mathrm{ND}$ & ND & ND & NL \\
\hline
\end{tabular}

Full blood counts, serum electrolytes, and liver function tests were normal in all subjects. IRT $=$ immune reactive trypsin; ND $=$ not done; Neg $=$ negative, $\mathrm{NG}=$ no growth $\mathrm{NL}=$ normal, $\mathrm{NPA}=$ nasopharyngeal aspiration, $\mathrm{pH}$ study $17 \%$ reflux $=$ total time below $\mathrm{pH} 4, \mathrm{RSV}=$ respiratory syncytial virus; para $2 / 3=$ parainfluenza virus type $2 / 3$. 
on barium swallow, but no clinical history to support significant gastro-oesophageal reflux or milk aspiration. A second infant had both mild reflux on barium swallow and a significant degree of reflux shown by a 24 hour oesophageal $\mathrm{pH}$ monitor. A gastroscopy and gastric and oesophageal biopsy samples in this infant showed mild gastritis. There was no suggestion of gastro-oesophageal reflux on clinical history, nor of aspiration lung disease on the subsequent lung biopsy sample. Nevertheless, this infant was treated with simple antireflux measures (thickened feeds) and cisapride, without any benefit. As a result of these investigations it seems unlikely that, in the five infants studied, aspiration lung disease was a significant part of the respiratory illness. In the remaining three infants no investigation for gastro-oesophageal reflux or aspiration was performed. As with the other infants, however, there was no clinical history to support this as a mechanism of their lung disease.

\section{Chest radiograph}

Seven of the eight radiographs showed abnormalities. Five showed hyperinflation (patients $1,2,3,7$, and 8 ), four showed perihilar alveolar shadowing (patients 2, 4, 7, and 8), and one showed bronchial wall thickening (patient 6). One radiograph (patient 5) showed no abnormality.

\section{Lung biopsy sample}

As the chest radiographs suggested a diffuse pathology, the site of the biopsy sample was left to the preference of the surgeon in seven infants (five had lingular biopsy samples, one had a biopsy sample of the base of the right lower lobe, and one of the left lower lobe taken). One infant underwent computed tomography of the chest which suggested that the hyperinflation spared the lingula. A biopsy sample was taken from the right lower lobe in this child. Six of the eight biopsy samples showed histological evidence of mild lymphocytic bronchiolar infiltration. The other two samples were normal. There was no archi-

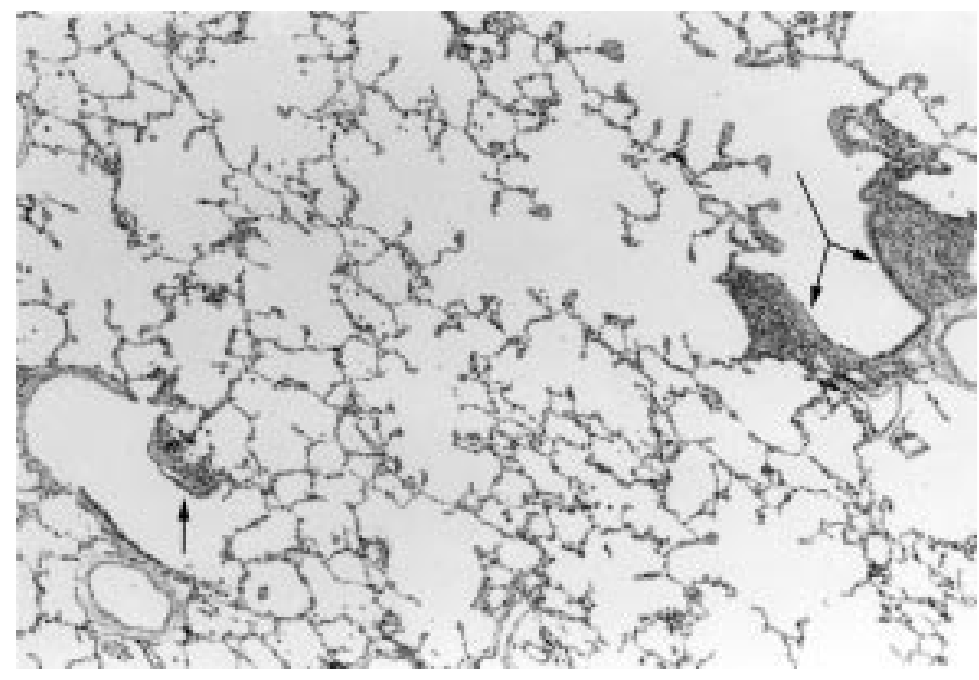

Figure 1 Lung biopsy sample showing mild lymphoid infiltration of the bronchioles (arrows) with no obvious abnormality of the alveolar architecture or narrowing of the bronchioles (haematoxylin and eosin; magnification $\times 75$ ). tectural disruption and in particular there was no evident fibrosis. There was no inflammatory change other than at the bronchiolar site. Figure 1 shows a typical biopsy sample.

\section{TREATMENT}

Seven of the eight infants were given a trial of steroids by mouth at $2 \mathrm{mg} / \mathrm{kg} /$ day (mean duration of treatment four months) without any apparent clinical benefit.

\section{OUTCOME}

The infants in this study have now been followed up for a median of 21 months (range 12-108 months). Of the five infants who required oxygen, three (cases 4,7 , and 8 ) no longer needed it after 14 months, four months, and four months, respectively. The remaining two subjects (patients 1 and 2) now need low flow oxygen $(0.1 \mathrm{l} / \mathrm{min})$ only at night and it is envisaged that this will be stopped in the next three months. So far these subjects have required oxygen for nine and 20 months, respectively. Seven of the eight subjects have had normal growth, although patient 4 continues to grow along the third centile. Patient 6 has had persistent poor growth (less than the third centile for weight, third centile for height). No cause has been found for her failure to thrive. All eight children have shown normal development.

At the six months' follow up, none of the subjects was tachypnoeic at rest. Three have subsequently reported breathlessness on exertion. It is possible that this figure will increase as the cohort becomes older. During the period of follow up the chest examination has become normal in four subjects (patients 2, 3, 4, and 7 at ages 19, 38, 18, and 14 months, respectively). In the remainder the inspiratory crackles have persisted, although they have decreased markedly in all cases. None of the subjects has been troubled by recurrent infections. Patient 8 has had intermittent wheezing requiring three hospital admissions. These episodes have not responded to bronchodilators. This subject is the only one who is old enough to perform lung function manoeuvres. The results of these tests indicated mixed mild lung disease.

The family of patient 3 had a subsequent child who developed a similar illness. $\mathrm{He}$ developed cough, poor feeding, and tachypnoea at 6 months of age. Examination revealed inspiratory crackles. A chest radiograph showed hyperinflation and perihilar bronchial wall thickening. Viral studies and barium swallow were negative. He required oxygen from 7 months of age. His family did not consent to a lung biopsy sample being taken. He was not given steroids and went home while receiving low flow oxygen treatment. He no longer needed daytime oxygen from 11 months of age, and his night time oxygen was stopped at the age of 14 months. His inspiratory crackles were still present at 20 months of age, although his growth and exercise tolerance were normal. 


\section{Discussion}

The clinical picture in these infants is one of chronic lung disease and five of the eight patients required prolonged supplemental oxygen treatment. Despite the apparent severity of the lung disease, only mild, non-specific changes were seen in the lung biopsy samples. It is possible that a sampling error is involved, although this seems unlikely given the generalised abnormalities seen on the chest radiographs. Only one infant underwent computed tomography of the chest; in this infant this investigation confirmed the hyperinflation and did not show any evidence of interstitial lung disease. The findings from the lung biopsy samples of bronchiolar inflammation, although mild, fits well with the clinical findings of hyperinflation and inspiratory crackles. The need for oxygen in five of the eight subjects presumably reflects a combination of alveolar hypoventilation and ventilation/perfusion mismatch.

The aetiology of the lung disease in these infants remains unknown. Several possibilities exist. The clinical findings could be explained by underdevelopment of the small airways in these infants, resulting in a predisposition to respiratory disease, perhaps brought on by a trivial and transient viral infection. In four of the eight subjects evidence of respiratory distress was present at birth, which supports the suggestion of a developmental abnormality. Subsequent improvement with age may reflect growth of the airways. An alternative is that the airways were initially normal, but were infected by an as yet unidentified pathogen. We are continuing to search for rare respiratory pathogens using polymerase chain reaction techniques.

Primary ciliary dyskinesia may occasionally present in infancy as unexplained respiratory distress. Although cilial function and structure were not examined in this study, abnormalities of bronchoalveolar lavage fluid, with increased inflammatory cells and positive bacterial culture, would have been expected.

A final possibility is that the illness reflects a subtle surfactant abnormality. Surfactant is present in the small airways and almost certainly contributes to the maintenance of small airway patency. The combination of the small bronchioles found in young infants and a minor surfactant abnormality may be sufficient to produce clinical disease. Again, with advancing age and airway growth it is possible that this type of defect could be overcome.

A possible genetic predisposition is suggested by the occurrence of siblings with apparently the same disorder. A common acquired environmental cause is not likely in this family as the second affected sibling was not yet born at the time the first developed symptoms.

The findings of the lung biopsy samples in this study were only mildly abnormal and have not been previously reported. The pathology which perhaps most closely resembles that described here is that of follicular bronchiolitis. This has been reported in young children, mostly in those with underlying connective tissue or immunodeficiency diseases. ${ }^{1}$ The lymphocytic infiltrates in this disorder are much more dramatic than those we describe here and are often associated with architectural disturbance, a finding that was completely absent in our study.

In conclusion, we have reported eight infants who presented with respiratory distress in the first year of life and whose illness was characterised by tachypnoea and inspiratory crackles. Extensive investigation did not identify the cause of this illness and lung biopsy samples typically showed a mild lymphocytic bronchiolar infiltration. There was a poor response to corticosteroid treatment. Despite five of the eight infants having respiratory failure requiring oxygen for some months, the medium term outcome has so far been favourable, although a longer period of follow up will be required to establish whether there are any long term sequelae.

JH was supported by an Advanced Training Fellowship from the Wellcome Trust, UK.

1 Yousem SA, Colby TV, Carrington CB. Follicular bronchitis/bronchiolitis. Hum Pathol 1985;16:700-6. 